\title{
MEPERIDINE INFUSION FOR POSTOPERATIVE ANALGESIA IN GROSSLY OBESE PATIENTS
}

\author{
J.S. SPRIGge, D.S.R. EAST, G.S. Fox, R.I. OGILvIE, P.E. OtToN \\ AND D.R. BEVAN
}

\begin{abstract}
Postoperative analgesia was provided to nine grossly obese patients with a continuous intravenous meperidine infusion. The narcotic was infused at an initial rate of $1.3 \mathrm{mg} \cdot \mathrm{min}^{-1}$ for 45 minutes, then $0.7 \mathrm{mg} \cdot \mathrm{min}^{-1}$ for 30 minutes followed by $0.5 \mathrm{mg} \cdot \mathrm{min}^{-1}$ for the next 24 hours. Pain was assessed at hourly intervals, serial blood samples were taken for measurement of plasma meperidine concentrations, and respiratory function was assessed by serial measurement of vital capacity and arterial blood gas analysis.

Analgesia was gradual in onset and from six hours after commencement of the infusion, seven of the patients suffered little or no pain. Plasma meperidine concentrations reached a peak of $0.33 \pm 0.05 \mu \mathrm{g} \cdot \mathrm{ml}^{-1}$ at one hour but decreased gradually after three hours. Surprisingly, there was poor correlation between analgesia and plasma meperidine concentration. All patients breathed spontaneously and maintained satisfactory blood gas tensions. However, there was a marked reduction in postoperative vital capacity.

Thus meperidine administered by continuous intravenous infusion can provide good postoperative analgesia in the obese patient without producing respiratory depression. However, the lack of correlation between analgesia and plasma narcotic concentration suggests that further study is required before intravenous regimes can be prescribed by application of pharmacokinetic principles.
\end{abstract}

Key WoRDS: ANALGESIA, postoperative; ANALGESICS, meperidine; ANALGESIA TECHNIQUES, intravenous infusion; COMPLICATIONS, obesity

UPPER ABDOMINAL SURGERY in the grossly obese patient presents several problems in postoperative care.' One of these is the relief of pain because, with effective analgesia, there may be a reduction in the impairment in respiratory function that follows upper abdominal surgery. ${ }^{2}$ This is particularly important in obese patients, whose respiratory function is already compromized. ${ }^{3}$

There are three commonly used techniques. Repeated intramuscular injections of opiates are easy to administer in patients who are not obese, but in the obese may result in injection into fat. Absorption of the drug is irregular and results in variable plasma concentrations which correlate poorly with the patient's absolute or lean body

J.S. Sprigge, M.B., B.Chir., F.F.A.R.C.S., D.S.R. East, B.Sc. Ph.D., G.S. Fox, M.D., F.R.C.P.(C), R.I. Ogilvie, M.D. F.R.C.P.(C), P.E. Otton, M.D., F.R.C.P.(C), D.R. Bevan, M.B. B.Chir., M.R.C.P., F.F.A.R.C.S., Department of Anaesthesia, Royal Victoria Hospital and McGill University, and Department of Clinical Pharmacology, Montreal General Hospital and McGill University, Montreal, Quebec, Canada. 142 weight. ${ }^{4}$ The parameters for calculating the optimal dose in an obese patient are less clear.

Epidural analgesia has been used ${ }^{1}$ but obesity may obscure the landmarks so that it is difficult to locate the epidural space. Smaller volumes of local anaesthetic solution should be used initially because the spread of the block may be exaggerated $^{5}$ and obesity predisposes to supine hypotension. ${ }^{6}$ Lastly, obese patients are prone to venous thrombosis and the prophylactic use of anticoagulants may make epidural analgesia hazardous. ${ }^{7}$

Intravenous administration of opiates by intermittent injection according to patient demand is effective in relieving pain after surgery ${ }^{8}$ and in obstetrics. $^{9}$ Continuous intravenous infusions with papaveretum have been shown to provide analgesia better than intramuscular regimes. ${ }^{10}$ Stapleton and his colleagues, using meperidine, reported that the continuous infusion technique provided rapid onset of analgesia with few side effects in women after hysterectomy. ${ }^{11}$ They found that there was analgesia when the blood meperidine concentration exceeded 0.46 $\mu \mathrm{g} \cdot \mathrm{ml}^{-1}$. However, narcotic drugs should be

Can. Anaesth. Soc. J., vol. 29, no. 2, March 1982 
used with caution in the grossly obese because it has been reported that they show abnormal sensitivity to respiratory depressants. ${ }^{12}$

The purpose of the present study was to evaluate the use of a continuous intravenous infusion of meperidine in providing postoperative analgesia in the grossly obese patient, to determine its effect on respiratory function, and to correlate the analgesia with the plasma meperidine concentration.

\section{METHODS}

The protocol was approved by the hospital Ethics Committee. With informed consent, nine grossly obese patients were studied after upper abdominal operations (gastroplasty 7 ; cholecystectomy 2). There were eight women and one man. Their ages ranged from 19 to 44 years (mean 32 years) and their weights from 90 to $143 \mathrm{~kg}$ (mean $118 \mathrm{~kg}$ ). In the preoperative period, each patient was visited and, in addition to the usual preoperative assessment, arterial blood gas tensions and vital capacity were determined with the patients sitting at $40^{\circ}$.

A standard non-narcotic anaesthetic technique was used for the operations. Premedication was with diazepam $20 \mathrm{mg}$ orally two hours preoperatively. Anaesthesia was induced with thiopentone $4 \mathrm{mg} \cdot \mathrm{kg}^{-1}$, followed by succinylcholine $1 \mathrm{mg} \cdot \mathrm{kg}^{-1}$ to facilitate tracheal intubation. Anaesthesia was maintained with nitrous oxide. oxygen and halothane $0.5-1$ per cent, pancuronium was given for muscle relaxation and ventilation was controlled. Muscle relaxation was reversed at the end of the operation and, when spontaneous ventilation had returned, the patients were extubated and admitted to the recovery room where they remained for 24 hours. They were supported sitting up in bed at $40^{\circ}$ and breathed 40 per cent oxygen in air.

After an initial satisfactory cardiorespiratory assessment, the meperidine infusion was commenced. A previously calibrated Harvard infusion pump was used to administer meperidine at the following rates: $1.3 \mathrm{mg} \cdot \mathrm{min}^{-1}$ for $45 \mathrm{~min}$ utes, then $0.7 \mathrm{mg} \cdot \mathrm{min}^{-1}$ for 30 minutes followed by $0.5 \mathrm{mg} \cdot \mathrm{min}^{-1}$ for the next 24 hours. This regimen was based on that of Stapleton, ${ }^{11}$ but the infusion rates were increased by an arbitrary 30 per cent to make some allowance for the increased weights of these patients.

\section{Assessment}

Pain was estimated at hourly intervals, using the pain score ${ }^{11}$ and the linear analogue techniques. ${ }^{13}$ With the pain score, the patients were asked if they had pain. If they said yes, they were asked if they wished more analgesia. Thus the pain score was graded into no pain, pain not requiring relief and pain requiring relief. With the linear analogue technique the patients indicated the severity of their pain on a $10 \mathrm{~cm}$ vertical line where the top represented extreme pain and the bottom represented absence of pain.

Respiratory Function was assessed by hourly measurements of vital capacity with the patients sitting at $40^{\circ}$ and by four-hourly blood gas estimations.

Plasma Meperidine Concentrations. Serial blood samples were taken and the plasma was extracted and stored at $-30^{\circ} \mathrm{C}$ for later estimation of plasma meperidine concentrations by high pressure liquid chromatography.

Results are expressed as means plus or minus the standard error of the mean (SEM).

\section{RESULTS}

Pain Relief. All patients had pain at the first recording of the pain score (Figure 1). By three hours, four patients still had severe pain, three had no pain and two had some pain. By six hours, seven patients had no pain and on the next morning six had no pain.

The mean linear analogue scores showed a similar decline, from $8.8 \pm 0.97 \mathrm{~cm}$ initially to $5.0 \pm 1.51 \mathrm{~cm}$ at three hours, $1.4 \pm 0.67 \mathrm{~cm}$ at six hours, and $1.7 \pm 0.73 \mathrm{~cm}$ next morning (Figure 2). Two patients failed to achieve analgesia at any time (Figure 1).

Respiratory Function (Figure 3). In the preoperative period, breathing air, the mean arterial oxygen tension was $10.8 \pm 0.6 \mathrm{kPa}$, the mean arterial carbon dioxide tension was $4.6 \pm 0.2$ $\mathrm{kPa}$ and the mean vital capacity was $2230 \pm$

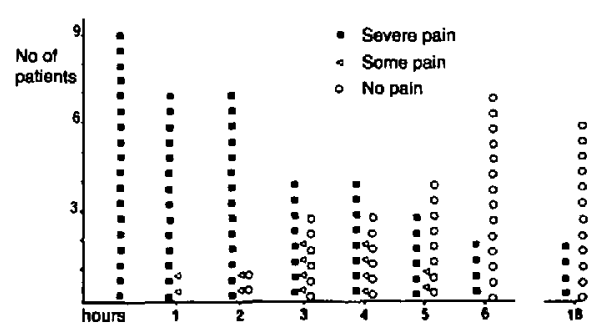

Figure 1 Pain Score. At hourly intervals, the patients were questioned about the amount of pain they had. Their responses are plotted over time. 


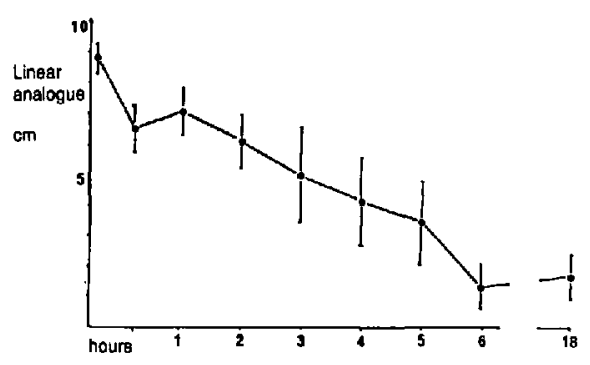

FIGURE 2 Linear Analogue Score + S.E.M. over time. With the linear analogue technique, the patient indicates the degree of pain experienced on a $10 \mathrm{~cm}$ vertical line, where $10 \mathrm{~cm}$ represents severe pain, and zero represents no pain.

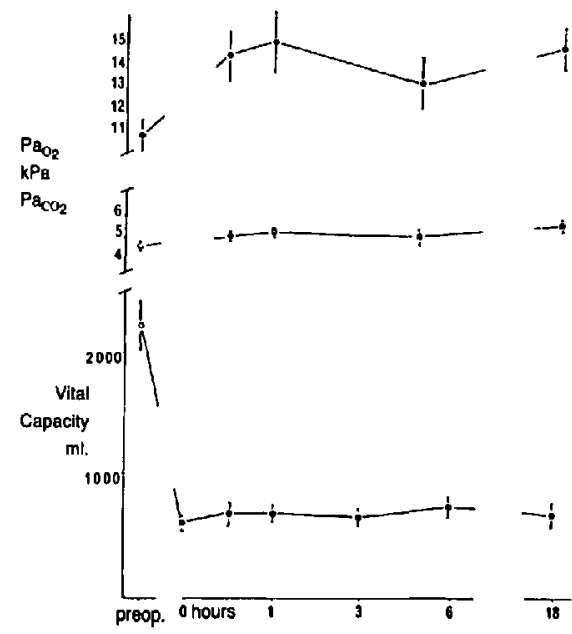

FIGURE 3 Respiratory Function over time.

$191 \mathrm{ml}$. Our patients were slightly hypoxaemic and their vital capacities were reduced on a $\mathrm{m} / \mathrm{kg}$ estimated normal body weight, which are frequent accompaniments of obesity. ${ }^{3}$ None had carbon dioxide retention.

In the postoperative period, the patients maintained arterial oxygen tensions between a mean low of $13.2 \pm 1.1 \mathrm{kPa}$ at five hours and a mean high of $14.8 \pm 0.9 \mathrm{kPa}$ at 18 hours when breathing 40 per cent oxygen. There was little improvement in this value with time. The carbon dioxide tensions rose from $5.1 \pm 0.2 \mathrm{kPa}$ at the first postoperative recording to $5.6 \pm 0.3 \mathrm{kPa}$ next morning. The highest value for carbon dioxide was $6.4 \mathrm{kPa}$ on one occasion in one patient and this sample was taken at 4 a.m. whilst the patient was asleep and breathing easily.
The vital capacity showed a marked decrease from the mean preoperative value of $2230 \pm$ $191 \mathrm{ml}$. The first postoperative recording was $605 \pm 33 \mathrm{ml}$, and the value the following morning was $712 \pm 75 \mathrm{ml}$.

Plasma Meperidine Concentrations (Figure 4). The plasma meperidine concentrations increased to a mean of $0.33 \pm 0.05 \mu \mathrm{g} \cdot \mathrm{ml}^{-1}$ plasma at one hour, and this concentration was maintained until three hours. After that, the concentration decreased to a mean of $0.30 \pm 0.1$ $\mu \mathrm{g} \cdot \mathrm{ml}^{-1}$ at four hours, $0.21 \pm 0.1 \mu \mathrm{g} \cdot \mathrm{ml}^{-1}$ at six hours and $0.08 \pm 0.02 \mu \mathrm{g} \cdot \mathrm{ml}^{-1}$ next morning.

The concentrations of the metabolite normeperidine showed a similar but delayed pattern (Figure 4), consistent with biotransformation of the parent compound.

Figure 5 shows the meperidine results superimposed on the linear analogue score (note that the linear analogue score has been inverted). There was no simple relationship between them.

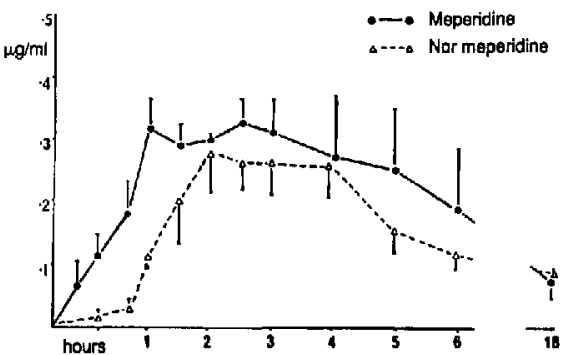

Figure 4 Plasma Meperidine Concentration over time. An intravenous administration of meperidine was given at $1.3 \mathrm{mg} \cdot \mathrm{min}^{-1}$ for 45 minutes initially, follawed by $0.7 \mathrm{mg} \cdot \mathrm{min}^{-1}$ for 30 minutes, and 0.5 $\mathrm{mg} \cdot \mathrm{min}^{-1}$ for the subsequent 24 hours.

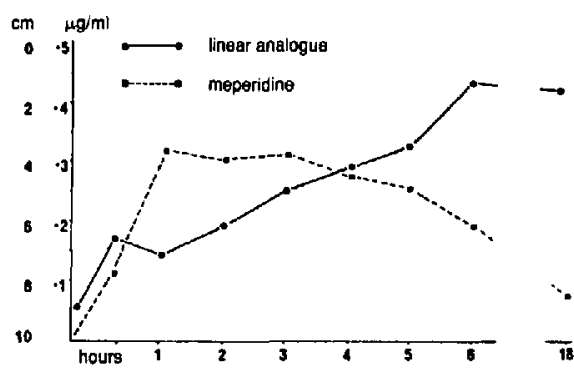

Figure 5 Analgesia and Meperidine Concentrations over time. Analgesia is represented by the linear analogue score (see Figure 2). In Figure 5, the score has been inverted, so that severe pain $(10 \mathrm{~cm})$ is at the bottom, and no pain $(0 \mathrm{~cm})$ is at the top. 
Analgesia was moderate when the mean plasma meperidine concentration was $0.3 \mu \mathrm{g} \cdot \mathrm{ml}^{-1}$ at four hours, but it was best at six hours, when the concentration had decreased to $0.21 \mu \mathrm{g} \cdot \mathrm{ml}^{-1}$. Analgesia continued to the next morning when the mean plasma meperidine concentration was only $0.08 \mu \mathrm{g} \cdot \mathrm{ml}^{-1}$.

No correlation was observed between meperidine concentration and vital capacity nor between pain score and vital capacity.

\section{Discussion}

Our infusion regimen was based on that of Stapleton and his colleagues. ${ }^{11}$ They provided postoperative analgesia in a group of women after hysterectomy with an infusion regimen designed to give a blood meperidine concentration excceding $0.2 \mu \mathrm{g} \cdot \mathrm{ml}^{-1}$ at 30 minutes and to reach 80 per cent of steady state within six hours. Analgesia occurred when the blood concentration of meperidine exceeded $0.46 \mu \mathrm{g} \cdot \mathrm{ml}^{-1}$. It was rapid in onset and well maintained, and was associated with few side effects.

In our group of patients, analgesia was similar in timing and effectiveness to Stapleton's study. "However, in our group, the plasma meperidine concentration increased to only 0.33 $\mu \mathrm{g} \cdot \mathrm{ml}^{-1}$ and was maintained at this concentration for three hours, after which it declined. Unlike Stapleton and his colleagues, we failed to find a close relationship between the plasma meperidine concentration and the maintenance of analgesia.

The lower steady state concentration reflects the larger volume of distribution in obese subjects which was not compensated by our arbitrary 30 per cent supplementation of Stapleton's regime. In addition, the gradual decrease in plasma concentration of meperidine after three hours suggests that its clearance may have been greater than anticipated. Clearly, further pharmacokinetic studies are required to determine the disposition of narcotics in the grossly obese. Nevertheless, the doses administered were sufficient for good postoperative analgesia.

\section{Analgesia and Plasma Meperidine Concentra. tion}

Previous studies have found a correlation between the onset of analgesia and the blood or plasma meperidine concentration. The values reported vary between $0.2 \mu \mathrm{g} \cdot \mathrm{ml}^{-1}$ serum for women who had tubal ligations, ${ }^{14} 0.46 \mu \mathrm{g} \cdot \mathrm{ml}^{-1}$ blood for post-hysterectomy patients ${ }^{11}$ and 0.73 $\mu \mathrm{g} \cdot \mathrm{ml}^{-1}$ plasma for patients who had laparatomies, ${ }^{8, *}$ differences which may be due to differences between the studies, different degrees of pain requiring different amounts of analgesia, or different analgesic requirements between patients. $^{16}$

Our study failed to find a concentration of meperidine that was associated with analgesia; five out of nine patients had some analgesia when the mean plasma concentration was 0.3 $\mu \mathrm{g} \cdot \mathrm{ml}^{-1}$ at four hours. Yet seven of nine patients had analgesia at six hours when the concentration had decreased to a mean of $0.21 \mu \mathrm{g} \cdot \mathrm{ml}^{-1}$.

Since meperidine acts at the central nervous system, the effect of the drug should be related more closely to the C.N.S concentration than to the plasma concentration. Before a clinical effect can be correlated with the blood concentration, there must be equilibrium between the blood concentration and the concentration of the drug at the site of action. ${ }^{17}$ In our patients, the continued decrease of the plasma drug concentration during the infusion period suggests that a steady state was not achieved. Another condition that must be fulfilled is that the clinical effect can be recorded accurately, whereas pain relief is difficult to estimate. ${ }^{18}$ Finally, the clinical effect should be produced by the drug action, and not by anything else. However, pain and analgesia are the products of the interactions of many neural pathways and neurotransmitters, and opiate sensitive synapses are not the only type of synapses involved in pain pathways. ${ }^{19}$

The design of this study made no allowance for the placebo effect. A placebo response will give analgesia in about 35 per cent of the population, but this percentage can be increased. ${ }^{20}$ Preoperatively, our patients were told about the purpose of the meperidine infusion by ourselves, and by other patients who had already had the infusion and were for the most part satisfied by it. Such conditioning might increase the incidence of placebo responses.

Respiratory Function. Postoperatively there was a marked reduction in the vital capacity to 25 per cent of the preoperative value and this did not improve over the next 18 hours. Bromage ${ }^{21}$ reported on the improvement that occurred in the vital capacity when a small group of patients who had undergone upper abdominal surgery received postoperative epidural analgesia. However, Smith and Spence ${ }^{2}$ studied patients who had upper abdominal operations and found that,

*The blood plasma coefficient for meperidine is 1.3:1 due to red blood cell binding. ${ }^{\text {is }}$ 
on the first postoperative day, the vital capacity fell to 30 per cent of the preoperative value: they found no difference in the vital capacities between the group who received epidural analgesia and the group who received intramuscular injections of morphine. Despite adequate analgesia these obese patients had significant decreases in spirometric tests of respiratory function. However no patient developed severe respiratory depression, so that the risk of abnormal sensitivity to respiratory depression in the grossly obese may have been exaggerated.

This study demonstrated that good analgesia can be achieved in grossly obese patients after abdominal operations with a continuous infusion of meperidine. This can be achieved without producing respiratory depression, although the decreases in lung volumes after abdominal surgery still occur. No direct comparisons were made with other analgesic techniques. However, simple observations of other patients suggests that the analgesia is as effective as that achieved with continuous epidural analgesia without the latter's technical and cardiovascular problems. Both methods seem to be superior to intermittent intramuscular injections of narcotics.

\section{REFERENCES}

1. Fox, G.S. Anaesthesia for intestinal short circuiting in the morbidly obese with reference to the pathophysiology of gross obesity. Can. Anaesth. Soc. J. 22: 307(1975).

2. SPENCE, A.A. \& SMITH, G. Postoperative analgesia and lung function: a comparison of morphine with extradural block. Brit. J. Anaesth. 43: 144(1971).

3. Farebrother, M.J.B. Respiratory function and cardiorespiratory response to exercise in obesity. Brit. J. Dis. Chest 73: 211(1979).

4. Austin, K.L., Stapleton, J.V. \& Mather, L.E. Multiple intramuscular injections: a major source of variability in analgesic response to meperidine. Pain 8: 47(1980).

5. HoDGKInSON, R. \& HUSAIN, F.J. Obesity and the cephalad spread of analgesia following epidural administration of bupivacaine for caesarean section. Anesth. \& Analg. 59: 89(1980).

6. TSUeda, K., Debrand, M., ZeOK, S.S. WRIGHT, B.D. \& GRIFFIN, W.O. Obesity supine death syndrome: reports of two morbidly obese patients. Anesth. \& Analg. 58: 345(1979).
7. Varkey, G.P. \& BRINdLe, G.F. Peridural anaesthesia and anticoagulant therapy. Can. Anaesth. Soc. J. 21: 106(1974).

8. Tamsen, A., Hartyig, P., Dahlström, B., LindSTRÖM, B. \& H:SON HOLMDAhL, M. Patient controlled analgesic therapy in the early postoperative period. Acta Anaesth. Scand. 23 : 462(1979)

9. Evans, J.M., MacCarthy, J., Rosen, M. \& HoGg, M.I.J. Apparatus for patient controlled administration of intravenous narcotics during labour. Lancet 1: 17(1976).

10. Catling, J.A., Pinto, D.M., Jordan, C. \& JONES, J.G. Respiratory effects of analgesia after cholecystectomy: comparison of continuous and intermittent papavaretum. Brit. Med. J. 2: 478(1980).

11. Stapleton, J.V., Austin, K.L. \& Mather, L.E. A pharmacokinetic approach to postoperative pain: continuous infusion of pethidine. Anaesthesia \& Intensive Care 7: 25(1979).

12. WEIL, M.H. \& PRASAD, A.S. Polycythaemia of obesity: further studies of its mechanism and a report of two additional cases. Ann. Intern Med. 46: 60(1957).

13. Bond, M.R. \& Pilowsky, I. The subjective assessment of pain and its relationship to the administration of analgesics in patients with advanced cancer. J., Psychosom. Res. 10: 203(1966).

14. SHIH, A.P.L., Robinson, K. \& AU, W.Y.W. Determination of therapeutic serum concentrations of oral and parenteral meperidine by gas liquid chromatography. Europ. J. Clin. Pharmacol. 9: 451(1976).

15. Mather, L.E., Tucker, G.T., Phlug, A.E., LindoP, M.J. \& WilkERSON, C. Meperidine kinetics in man. Clin. Pharmacol, and Therap. 17: 21(1975).

16. Austin, K.L., Stapleton, J.V. \& Mather, L.E. Relationship between blood meperidine concentrations and analgesic response. Anesthesiology 53: 460(1980).

17. Hull, C.J. Pharmacokinetics and pharmacodynamics. Brit. J. Anaesth. 51: 579 (1979).

18. Nayman, J. Measurement and control of postoperative pain. Annals Royal College Surgeons of England 61: 419(1979).

19. Bowsher, D. Pain pathways and mechanisms Anaesthesia 33: $935(1978)$.

20. Melzack, R. Psychological concepts and methods for the control of pain. Advances in Neurology 4: 275(1974).

21. BRomage, P.R. Spirometry in assessment of analgesia after abdominal surgery: a method of comparing analgesic drugs. Brit. Med. J. 2: $589(1955)$.

\section{RÉSUMÉ}

On a administré l'analgésie post-opératoire à neuf patients souffrant d'obésité extrème en utilisant une perfusion continue de mépéridine. Le narcotique a été perfusé à la vitesse initiale de $1.3 \mathrm{mg} \cdot \mathrm{min}^{-1}$ pour 45 minutes, $0.7 \mathrm{mg} \cdot \mathrm{min}^{-1}$ pour 30 minutes et finalement de $0.5 \mathrm{mg} \cdot \mathrm{min}^{-1}$ pour les 24 heures suivantes. La douleur a été évaluée à toutes les heures, des échantillons sanguins ont été prélevés en série pour la mesure du taux plasmatique de 
mépéridine et de la dépression respiratoire a été évalucée par des mesures répétées de la capacité vitale et par l'analyse de gaz artériels.

L'analgésie a débuté graduellement et six heures après le début de la perfusion, sept des malades ne ressentaient que peu ou pas de douleur. Le taux plasmatique de mépéridine a atteint un sommet de $0.33 \pm 0.05 \mathrm{mg} \cdot \mathrm{ml}^{-1}$ après une heure mais a diminué graduellement après trois heures. Il a été surprenant de constater la pauvre corrélation entre l'analgésie et le taux plasmatique de méperidine. Tous les malades respiraient spontanément et ont maintenu des gaz artériels satisfaisants: ainsi on en conclut que la mépéridine administrée en perfusion continue peut fournir une analgésie post-opératoire de qualité au patient obèse sans causer de dépression respiratoire. Cependant, le manque de correlation entre l'analgésie et la concentration plasmatique porte à croire que des études supplémentaires sur la pharmacocynétique sont nécessaires avant de recommander l'application d'un tel régime. 